\title{
HOW A BETTER REPRESENTATION OF CONTRACTUAL RELATIONS CAN HELP TO DESIGN BETTER CONTRACTS
}

\author{
S. Bolifraud ${ }^{1,2, \bigotimes}$, J.-C. Cryonnet ${ }^{2,3}$ and J. Stal-Le Cardinal ${ }^{1}$ \\ ${ }^{1}$ CentraleSupélec, France, ${ }^{2}$ Leynaud \& Associés, France, ${ }^{3}$ SyRHèse, France \\ $\square$ bolifraud.sylvain@gmail.com
}

\begin{abstract}
This paper contributes to the reduction of conflicts arising along the construction process by improving contract management tools and contracts designing tools. We analyse the existing system of representation of relations between Owner and Contractor, the contract and the construction processes. We improve the actual representation of construction processes by creating a link with the contract. Our ambition is to create a representation that will allow organizations and project managers to represent the construction contracts and design better construction contracts.
\end{abstract}

Keywords: construction industry, contract management, complexity, design knowledge, cognitive capabilities

\section{Introduction}

The theme of this article is to improve the knowledge of an actor involved in a contractual relationship during a construction operation and to help the design of better contracts. Our goal is to contribute to the reduction of conflicts arising along the construction process by improving practical contractual management tools. We propose to explore the ways in which the operational and termination content of the contracts are represented and schematized.

It is widely believed that the construction industry has an opportunistic, conflict-prone and changeresistant culture (Rooke et al., 2004). To go beyond these commonplaces, even if it must be noted that conflict situations seem inherent to divergent interests (Wong et al., 2008), it seems appropriate to question the origins of conflicts and the factors of their evolutions.

The origins of conflicts arising during the execution of a contract can be identified:

- either in the terms of the contract

- either in the completeness of the contract,

- or in the very use of the contract.

These conflicts will evolve according to the preponderance of factors related more to the actors than to the original circumstances. These factors are opportunism, uncertainty, and limited rationality. In 2019, it has been shown that the elements causing the greatest deviations in judgment from the actors of construction project relate to elements for which it is difficult to assess the achievement or to find evidence of non-desired behaviour (Bolifraud and Stal-Le Cardinal, 2019), this corresponds perfectly to the factors mentioned above and puts information asymmetry at the centre of the issue. 
Information asymmetry is recognized as the main source of conflict linked to the temptation to be opportunistic. In recent years, many papers have attempted to highlight the role that trust can play in contractual relationships and how trust would reduce opportunistic behaviour and thus reduce conflict. This approach reduces the origin of information asymmetry only to a bilateral differential and its consequences to the opportunism of one of the actors. Yet the contractual situation is more complex, the sources of information and knowledge are distributed according to levels of complexity and in a fabric of actors that goes beyond a simple bilateral framework. The problem, specific to the construction operation, then shifts from trust to the use and consideration of the information and knowledge of the actors, in the three-following environment of complexity of Boirel:

- the internal environment: the bilateral contract,

- the external environment: the interactions of the operation,

- the external context.

These three levels of complexity will have to be taken into account in the representations and schematics of the contract.

After developing our problematic, our paper explores the systemic representation of a "construction project contract" system. It helps us to determine the different axis which need to be studied, in a third party through a state of the art we present the representation of the different environment of complexity we find in the literature. Then we propose an improvement of the external environment by improving the process design and creating a link with the internal environment. We conclude with a proposition of representation and schematization tool that will allows actors of a project to improvement their knowledge of the contract and their contractual relations.

\section{Problematic}

\subsection{Source of conflict}

In recent decades, much research has been done on the nature of the conflicts arising during the execution of commercial contracts. Among these papers, special attention is given to the subject of opportunism as a source of conflict.

Two types of opportunistic behaviour are identified, opportunism ex-ante and ex-post. Ex-ante opportunism is based on information asymmetry, undisclosed information, or erroneous information given before the contract, Akerlof then speaks of "adverse selection"(Akerlof, 1978). Ex-post opportunism is the use to the advantage of part of the cost of the control necessary for the counterparty to demonstrate non-compliance with contractual obligations, we speak here of "moral hazard".

As Cox recalls,

the litmus test for successful management should not be whether the project was free of changes or claims, few projects would pass that test - but, rather, if change orders and claims were resolved in a timely manner to the benefit of all the parties and the project (Cox, 1997).

From this conclusion emerges that the contractual problem is primarily that of ex-post adaptation (Brunet and César, 2014). Our analysis will therefore be based on the execution phase of the contract.

Combined with ex-post opportunism, we must reckon with uncertainty, construction projects are particularly long and many elements can occur and disrupt the course of the project, this uncertainty which is reinforced by the complexity of the contracts, with clauses that cannot be interpreted independently from each other (Brunet and César, 2014) and their incompleteness, it is not possible to anticipate everything, the cost of writing and executing a complete contract would be too excessive (Brunet and César, 2014).

To the ex-post opportunism, to the uncertainty about the events and the incompleteness of the contract, we must also add various limitations such as the limited rationality of individuals and organizations, and the limitations in resources (time, means).

Faced with this situation, several researchers have highlighted the role of trust in contract formation. For Williamson, trust is unnecessary and misleading because it conceals the reality of a decision- 
making process based on economic calculation (Williamson, 1993). However, when we talk about cooperation, trust is central and even more necessary because the contracts are incomplete. To get a clearer picture, we can look at trust in three ways:

- System-based trust, which focuses on formalized and procedural arrangements with no consideration on personal issues (Lewis and Weigert, 1985). The three major components of system-based trust are organizational policy, communication system and contract agreements (Wong et al., 2008).

- Cognition-based trust develops from the confidence built upon knowledge that reveals the cognitive bearings of an individual or an organization (Wong et al., 2008).

- Affect-based trust describes an emotional bond that ties individuals to invest in personal attachment and to be thoughtful to each other (Lewis and Weigert, 1985)

Let's examine these three components of trust and see how a project manager can deal with in real life.

A project manager who has to start a new contract usually does not participate in commercial negotiations and discovers the contract after it has been signed, regardless of his level of confidence in the contract it is no longer possible for him to change it. The choice of the individuals with whom he will have to deal with is not part of his prerogatives, so the same as for the contract, project manager can have a very low influence on the personality and individuals he will have to deal with. Thus, the only real aspect on which it is possible to act is the cognition-based trust by improving its knowledge and creating tools for the organization.

Our interviews with various professionals and our experiences allowed us to pinpoint the origins of conflicts arising during the execution of a contract on three main sources:

- either in the terms of the contract (error, omission, ambiguity, leonine clauses) (Cause 4 in the Figure 1),

- either in the incompleteness of the contract, editorial incompleteness with the absence of the necessary resolution clauses, projective incompleteness with the absence of the descriptions and prescriptions necessary for the execution of the works, or incomplete in the lack of robustness of the contract to the hazard and more generally to the uncertainty present in the context of the construction operation. (soil, time, unavoidable changes given the generally long duration of operations) (Causes 4 and 5 in the Figure 1).

- or finally in the very use of the contract which can sometimes be misunderstood, often poorly or not applied and sometimes even ignored (Causes 1, 3 and 6 in Figure 1).

We can confirm our comprehension of the causes of conflicts with a compilation of the results of the empirical study conducted by the company Arcadis and updated each year through the "Global Construction Disputes Report" (ARCADIS, 2013, 2014, 2015, 2016, 2017, 2018, 2019). Figure 1 summarizes the results of the study from 2012 to 2018, the highest scores represent the most common causes in a given year.

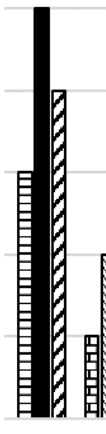

2012

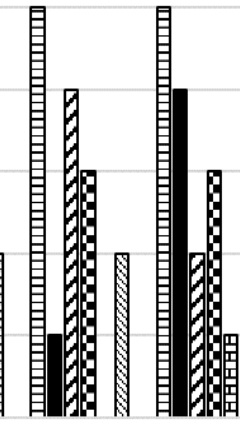

2014

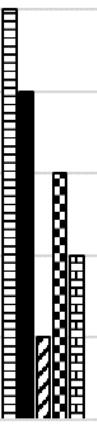

2015

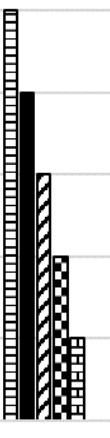

2016

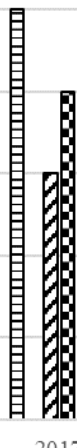

2017

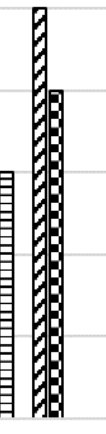

2018
日1 - Failure to properly administer the contract

- 2 - Poorly drafted or incomplete and unsubstantiated claims

a 3 - Failure to understand or comply with its obligation

घ 4 - Errors and/or Omissions in the contract document

Q5 - Incomplete design information or employer requirements (for DB )

$\mathbf{8} 6$ - Failure to make interim awards on extensions of time and compensation

Figure 1. Synthesis of Arcadis's Global Construction Report from 2012 to 2018 
The cause "Poorly drafted or incomplete and unsubstantiated claims" could be merged to the cause "Failure to understand or comply with its obligation", as making incomplete claims may be akin to an inability to understand or meet its obligations.

\subsection{Contradictory adjustment}

As we have seen previously, the construction project is uncertain, the contract is inherently incomplete, and each actor uses every deficiency he finds in the contract as an opportunity to improve his position.

Past engineers were fully aware of this problem and to counter them, they introduced different clauses in the contracts to deal with changes and uncertainties.

This confirms that the claim is a normal process in construction. But it is integrated into a more comprehensive process of adjusting the forecast description of the work to be performed and the contractual prescription in relation to the reality of the realization of the work. This overall process begins with a contradictory adjustment phase through the application of contractual clauses and modification of the contract, continues with claim and dispute phases, which are phase of negotiations and mediation and ends with conflict phases through litigation in the competent jurisdiction, as described in Figure 2 below.

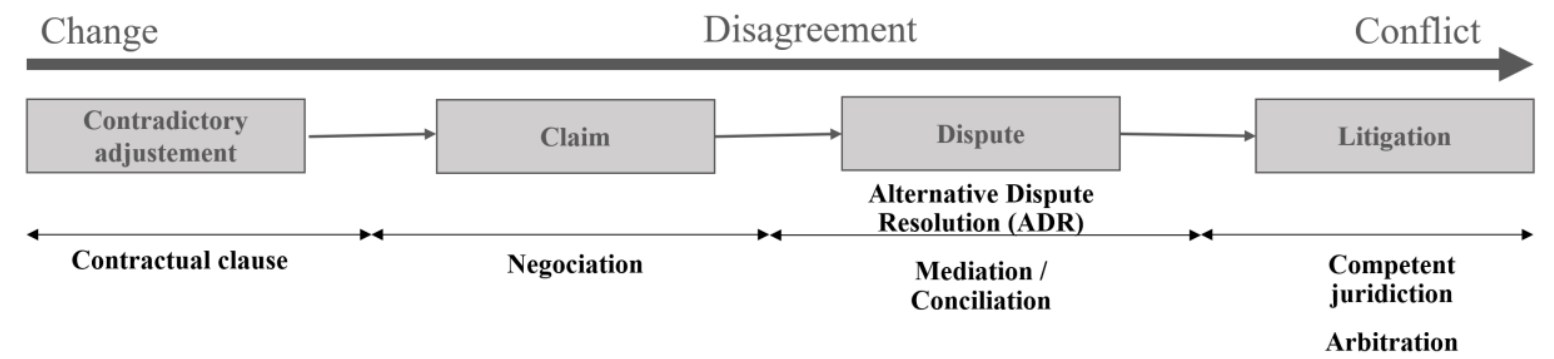

Figure 2. From change to conflict

\subsection{Conclusion on problematic}

From the previous paragraphs, it appears that to consider the contract and the project as something fixed is not a good approach. First, the uncertain aspects of the project will become certain as the project progresses (estimation gets better as a project progresses, this concept is well known and called the cone of uncertainty (McConnell, 1996)), and then as the project changes, the contract should follow this change, at each stage of the project, the opportunistic behaviour must be treated..

Construction industry is an incredibly old business, in comparison with manufacturing industry, generally legal systems already deal with the matter, it leads with the creation of standard forms of contract for public and private sector. Stakeholders of a construction contract deal with four situations, the use of a standard form of contract, the use of a modified standard form of contract, the use of a "from scratch" contract and finally the absence of contract. In each of these four situations, the understanding and the knowledge of the obligations, the ability to process information, the improvement of cognitive processes are sources of progress in limiting contractual risks.

\section{Research question}

It is well known that engineers are more focus on solving technical problems, it is the main reason about becoming an engineer. Contract is seen as a lawyer tool. Here we have the confrontation of two worlds and two separate ways of looking at the same object. We propose to reduce inherent risks of misinterpretation, misunderstanding and ignoring adjustment clauses in the contractualization phase by a translation of the contract in a representation that will allow a better understanding. We suppose that it will lead to the designing of more secure contracts.

Our exploration focus on the possibilities of representing contractual situations, how they arise, the communication procedures and the exchange procedures they require taking into account the knowledge, information and data in all three environments of complexity of a construction project contract. Our research question can be summed up as follows: Is it possible to give actors a representation of their 
contractual relationship that allow them to improve their knowledge of the contract and the interactions they have with their environment?

This question is essential in the industrial world, in all sectors combined. Indeed, as soon as we have a customer-supplier relationship in an industrial project, in product design, in supply chain, in construction, the question of interaction between actors is crucial and the knowledge of the stakeholders and the issues involved also."

\section{Research methodology}

The "construction project contract" system as we elaborate it based on our research and our experiences is represented in Figure 3. To represent our construction project contract system, we use a formalism inspired from NIAM method (Natural Language Information Analysis Method). This model Entity-Relation allows to describe the data under object, represented in rectangle and to represent link between represented by ellipse. With this method we represent the 4 axis of systemic analysis, genetic axis (Bottom right), functional axis (bottom center), ontological axis (Bottom left) and teleological axis (Top) Each axis is built on definition and knowledge of construction industry.

We distinguish 3 groups of elements: Relation between Owner and Contractor, the contract itself and the construction processes.

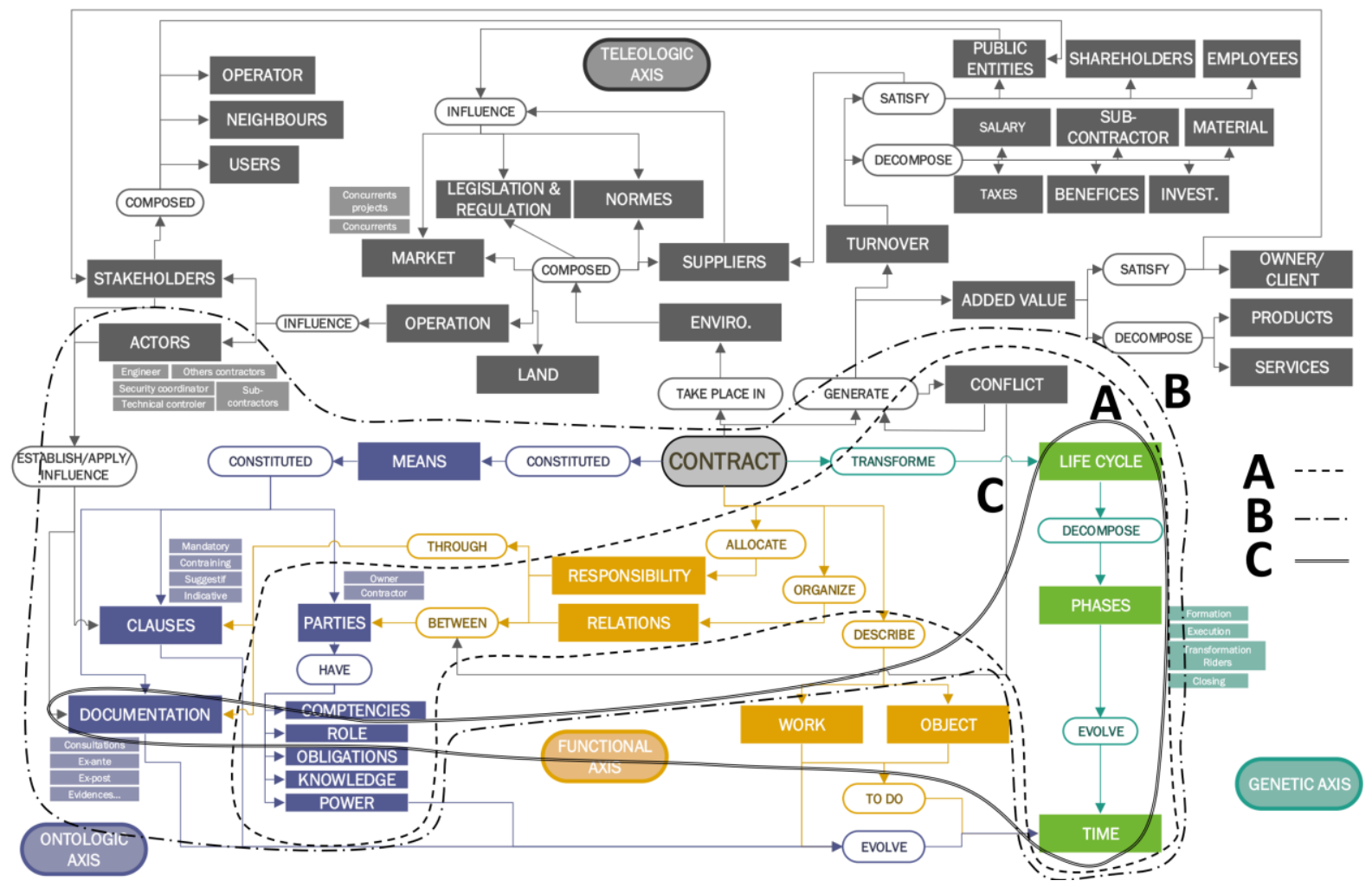

Figure 3. Representation of the system "construction contract" - proposition

Group A is about relation between Owner and Contractor, this aspect has been treated through FAcT Miror analysis a presentation of this work can be find in the paper "How a Better Understanding of Relation can Increase Responsibility between Stakeholders?" presented at ICED19 (Bolifraud and Stal-Le Cardinal, 2019). Group B deals with the contract itself and how it manages the relation between the parties to the project all along its life cycle, Group B is presented in part 5.1, Group C is about construction processes, it is developed in part 5.2. We address the teleological axis in part 5.3.

Our research method has been to find in the literature attempts to represent construction processes, construction contract management processes and analysis of the links between construction projects and their environment. 
This systemic representation places the contract in the middle of a larger environment than the simple relation between 2 actors, it places the contract in the middle of an operation which is constituted of other contracts, in an unpredictable physical environment. The Figure 3 has been presented in different workshops with professionals and has been recognised as a good tool to understand the position of an actors in an operation.

\section{State of the art}

Boirel proposes to distinguish 3 levels of interaction spaces in the relationship of the system to its environment. These 3 levels are called the internal environment, the external environment and the surrounding environment (Boirel, 1961). The Figure 3 shows that construction project contract can be considered as a system so we propose the identification of 3 levels of complexity, the bilateral contract between the Owner and the Contractor represents the internal environment (Group B), interactions with the construction project represent the external environment (Group C), and finally the relation with the surrounding environment. These three environments of complexity are schematized in Figure 4.

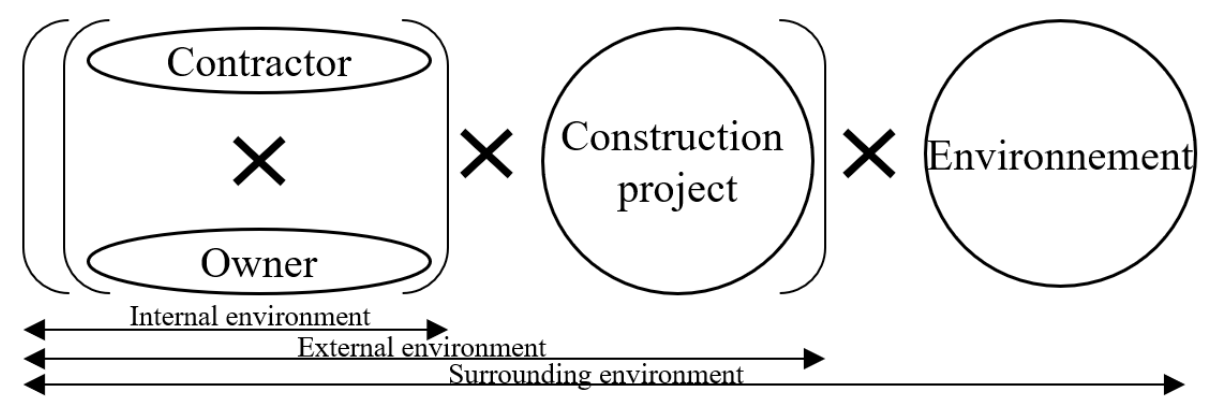

Figure 4. The three environments of Boirel applied to the construction contract system

We therefore focused our research on the adequate existing tools of representation of the 3 environments independently of the others by identifying past attempts and comparing their results with our expectations.

\subsection{The internal environnement - construction contract management process}

On the aspect of the representation of the contractual relationship and its management we found few relevant elements. Most of the representations and models we found are studies aimed at computerizing the management of contracts for goods and services where contractual relationships and dysfunctions are well predictable (for example phone subscription). These studies are therefore not aimed at complex contracts for complex projects.

Also, these studies have the aim to reduce human intervention in the process. In this they take us away from our primary objective, which is not to save an operator time but to gain knowledge and control for the project team.

We have identified a study that deals with the construction of a contractual knowledge base by encoding contractual clauses using a Defeasible Logic framework (Wang and Governatori, 2007). The paper presents the logical encoding of clause 67 of the fourth edition of FIDIC contract published in 1987.

FIDIC is the acronym of International Federation of Consulting Engineers (The abbreviation represents the French version of the name), founded in 1913, FIDIC is now an international association and publish a series of standard contract forms. These forms have become international standards in civil, mechanical, electricity and medicine engineering projects. Clause 67 explains the procedure to follow in case of a dispute between the Contractor and the Employer (Owner) in a FIDIC contract.

The article concludes that the method used appears to be able to be applied to any standard contract to allow the construction of a contractual knowledge basis. The construction of knowledge base is a first step, but as to own a dozen of different dictionaries at home doesn't prevent you from doing spelling mistakes, we think that knowledge basis doesn't help you to gain a better understanding of your contractual relations on a specific project. 
This study doesn't give any representation or schematization of the results, but it confirms that operating logics can be used to represent contractual relationships through the clauses of the construction contract, it also demonstrates that it is possible to incorporate external actors as Engineer or Controller.

\subsection{The external environment - construction process}

In 1997, a representation of the complete construction process based on IDEF0 was proposed (Karhu et al., 1997) (Figure 5). The focus was on the improvement of the coordination and performance of the construction process

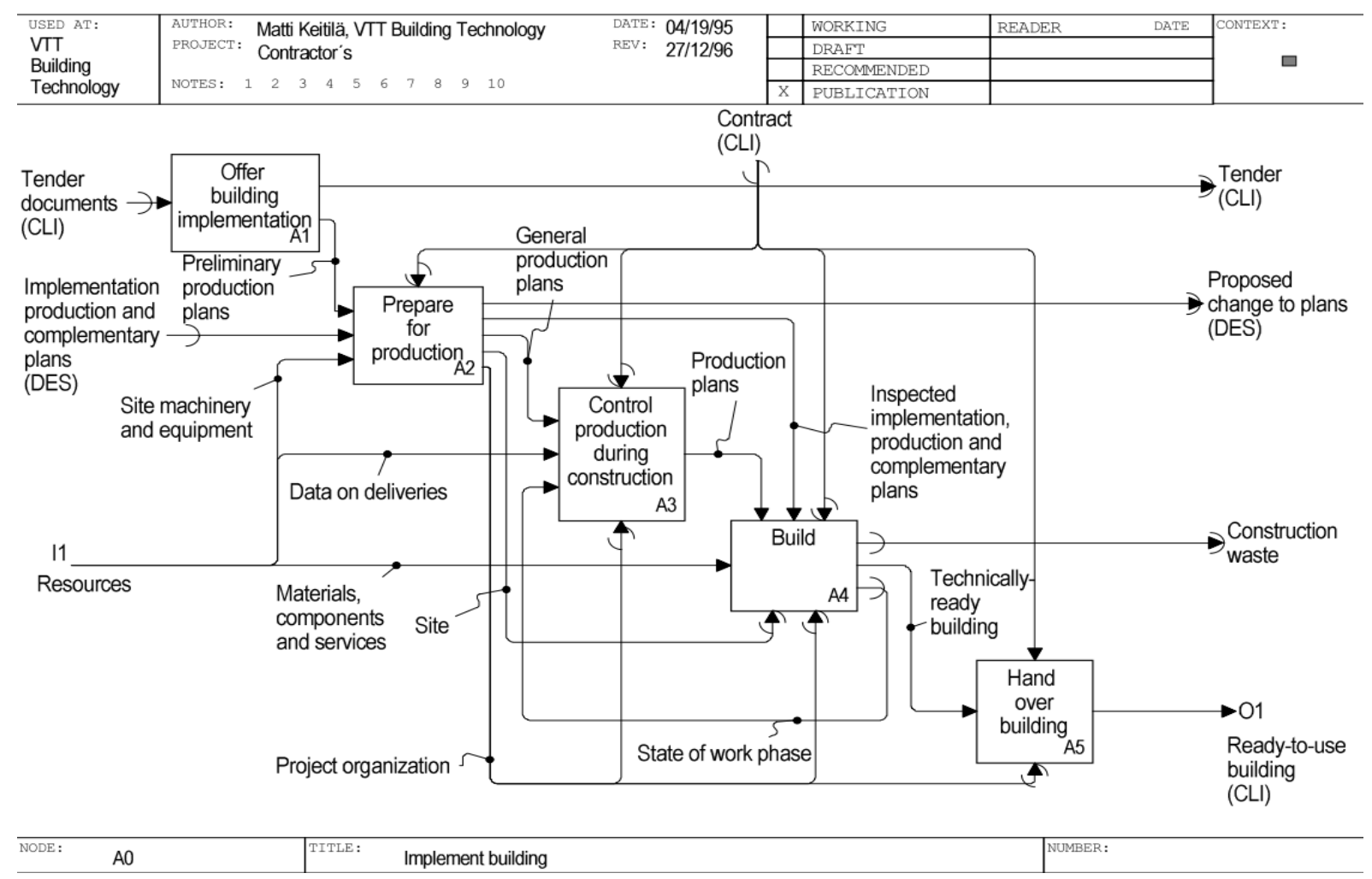

Figure 5. Construction project implementation processes (Karhu et al., 1997)

The IDEF0 is designed to model the decisions, actions and activities of an organization or manufacturing system in a structured graphic form (Kim and Jang, 2002). It provides users with a powerful analysis and development tool for manufacturing companies.

\subsubsection{Opinion on the choice of method}

IDEF0 is a tool created to allow the representation of a manufacturing organization. Some would be tempted to view the construction operation and the actors who contribute to it as a full-fledged organization working towards the same objective, but it is necessary to remember that every actor on a construction project has different or opposed interests from those of other actors and as such acted on his needs and objectives.

For us to consider the construction project as an organization is an error. It implies obscuring the three sources of complexity of the construction contract that are the internal environment (the bilateral contract), the links with external environment (the construction project) and the surrounding environment.

This IDEF0 method has many flaws, but we identified two flaws that are fundamental to deal with construction projects. On one hand IDEF0 confines to a purely mechanistic view of operations that ignores the management of uncertainties and tools already existing to deal with them (as the contract) and on the other hand it does not deal with relations with external organizations. 


\subsubsection{On the choice of the processes represented and their layout}

We disagree with the sequential vision of the construction operation. A construction operation aggregates various functions. Some are successive but others such as management functions are carried out in parallel with other activities. Also, these management functions are made up of several activities, we believe it is necessary to distinguish the activity of setting up the management systems of the operation, from the activities of monitoring the operation. This corresponds more to the reality of the field in that the implementation of management systems is carried out by management and follow-up activities by lower hierarchical levels.

Sequential vision, however, has an advantage in highlighting the control elements necessary for a process to run smoothly. Strictly speaking, the absence of an element of control will prevent the process from being carried out, but in a more general sense, the absence of one element may lead to the potential misperformance of a process and thus to the emergence of disagreement and conflict.

Finally, this representation does not highlight the active role of the contract as well as its intrinsic dynamics which are the two aspects of contractual "mechanisms" on which we suggest orienting the attention of the actors.

In point 6 we propose an improvement in the representation of the implementation phase of the construction project which shows a parallelization of management processes and reveals a process of contract management, this create the beginning of a link between Group B and C of Figure 3 .

\subsection{The surrounding environment}

To date, the exploration of the modes of representation of the surrounding environment has not allowed us to find any relevant elements on the operational side. The analysis of the teleological axis of our system (Figure 3) reveals a great complexity of elements to be considered.

Schedule system can be a beginning of answers to link the work to be done in a contract with the work to be done on the global operation, but this tool is too limited and to specific to embrace the more global elements of teleological axis.

In conclusion, on this aspect, our work is still on going.

\section{Proposition of improvement for helping to design new contracts}

To do so we propose an improvement of the representation of the external environment and we introduce a link with the interior environment. We propose an improvement in the representation of the implementation phase of the construction project which shows a parallelization of management processes and reveals a process of contract management. This allows to introduce an uncertainty management process throughout the construction process.

This requires first parallelizing the management processes with the production process, and then the IDEF0 diagram must be completed by a process dedicated to contract management.

From now on, the contract is no longer a passive entry, but becomes an active tool necessary for project management as a process is dedicated to manage its changes along the construction process.

The introduction of a changes management process which lead to a contract management process requires that the contract be put back at the centre of the relation between the Owner and the Contractor.

By extension, this makes it possible to refocus the relationship on the decision-making process and the sharing of responsibilities necessary for this decision-making process.

Until now, the understanding of a student or a young practitioner of construction process is based on a succession of technical operations, the focus is on the production process. The contract is seen as a fixe element and never used as an evolving one and never see as a tool.

A look to the Figure 5 allows to see that the contract is represented as a controlling element, we see no process to modify it.

The new representation on Figure 6 shows that before implementing a change on a construction project, you should manage your contract and then give the order to execute the change. 


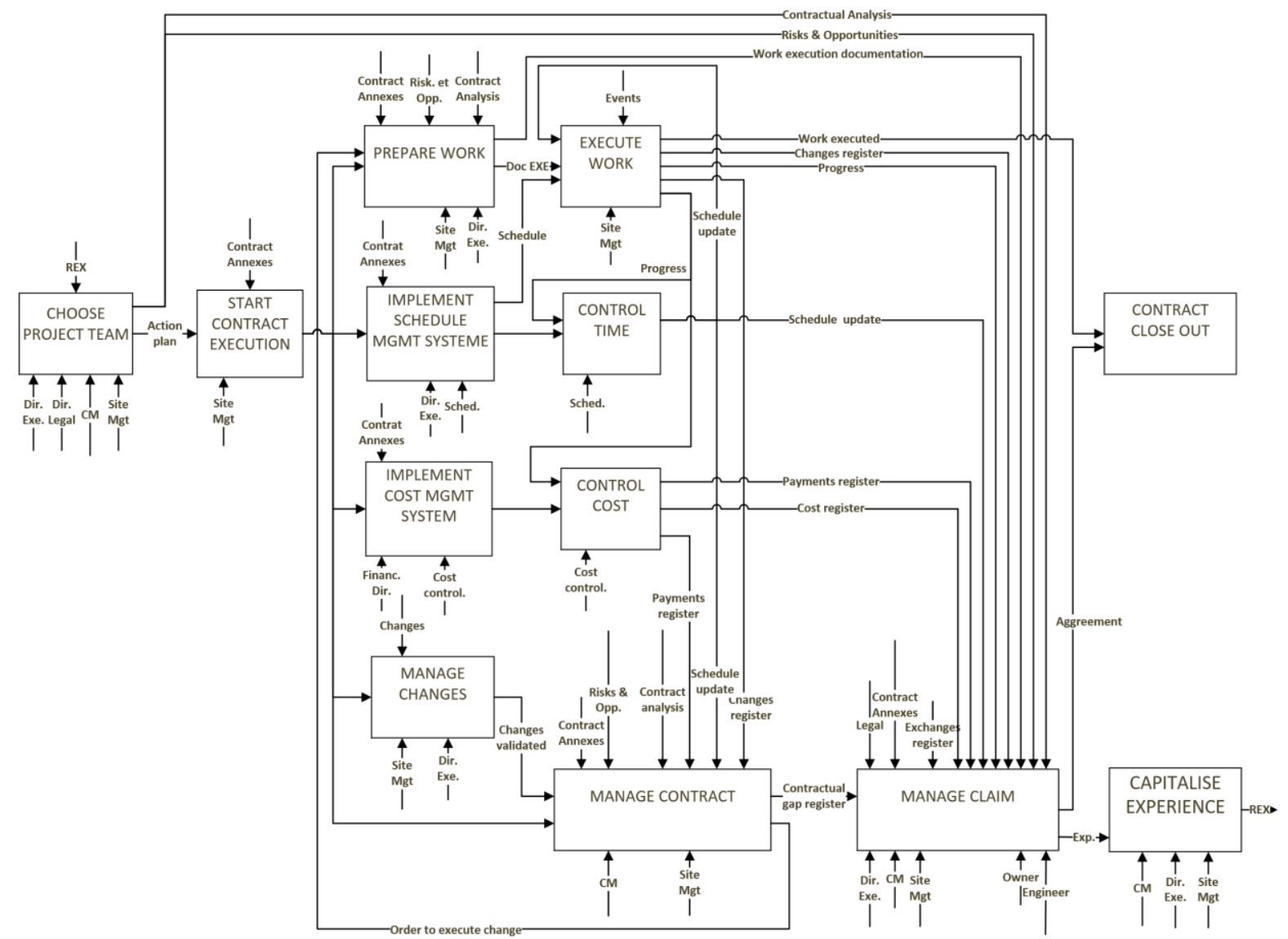

Figure 6. Proposition of improvement on construction processes

Figure 6 is the result of an on-going work, it necessitates to be evaluated. Nonetheless, Figure 3 and 6 have been presented and discussed in professional conferences and we already have verbatim from some participants, from the ENGIE's PMO Director : "Very beautiful and enriching intervention by Sylvain BOLIFRAUD around some concepts related to claim management" and from a technical expert in French court "The presentation was very interesting for a subject that is generally little taught, and rarely the subject of research, when it seems to constitute an increasingly used management tool.

\section{Conclusion}

Along this paper, we explore the causes of conflicts between Owner and Contractor on construction projects, we determine that the only true element on which an actor has influence to improve his position is by improving his knowledge and understanding of the contractual relation and of the context of the contract.

Based on a representation of a construction contract system, we show three environments of complexity. By exploring the existing representation system and tools to manage these three levels of complexity we highlight that a global unified operational representation does not exist.

Nonetheless, we propose an improvement of the mechanist view of IDEF0 used to represent construction processes by creating a link with the internal level of complexity represented by the contract. This allows a repositioning of the decisional process on the centre of the relation.

As we explain before, IDEF0 has a lot of flaws and appears to not be the adequate tool for construction contract management process. We need to orient our researches on tools that allow multiorganizations and multi-actors representation. We also need to incorporate an operational process of decision linked to the contractual clauses, documentations, and surrounding legislation.

Today a path seems to lead to the OSSAD representation system. OSSAD is the result of a European research project carried out from 1985 to 1989 as part of the ESPRIT programme. OSSAD works with 
two levels of representation, an abstract level which gives a relative liberty of representation, and a descriptive model, which describes and organizes processes, resources, roles, tools, this level can be decomposed in three representation, activity-role matrices, information circulation graph, and operational graph.

Our ambition is to create a representation that will allow organizations and project managers to represent the contracts they have to deal with. This tool will allow the representation of standard forms of contract and to identify exhaustivity, or at least, flaws on new forms of contracts or on modified forms.

We propose to present in DESIGN20 our progress on this aspect.

\section{References}

Akerlof, G.A. (1978), “The Market for 'Lemons': Quality Uncertainty and the Market Mechanism”, Uncertainty in Economics, Vol. 84, Academic Press, Inc., available at: https://doi.org/10.1016/b978-0-12-214850-7.50022-x

ARCADIS (2013), Global Construction Report 2013.

ARCADIS (2014), Global Construction Report 2014.

ARCADIS (2015), Global Construction Report 2015.

ARCADIS (2016), Global Construction Report 2016.

ARCADIS (2017), Global Construction Report 2017.

ARCADIS (2018), Global Construction Report 2018.

ARCADIS (2019), Global Construction Report 2019.

Bolifraud, S. and Stal-Le Cardinal, J. (2019), "How a Better Understanding of Relation can Increase Responsibility between Stakeholders?", Proceedings of the Design Society: International Conference on Engineering Design, available at: https://doi.org/10.1017/dsi.2019.121

Brunet, A. and César, F. (2014), Le Contract Management, Eyrolles.

Cox, R.K. (1997), "Orders and Claims", No. February, pp. 24-29.

Karhu, V., Keitilä, M. and Lahdenperä, P. (1997), "Construction Process Model", Generic Present-State Systematisation by IDEF0, VTT Tiedotteita - Valtion Teknillinen Tutkimuskeskus.

Kim, S.H. and Jang, K.J. (2002), "Designing performance analysis and IDEF0 for enterprise modelling in BPR", International Journal of Production Economics, Vol. 76 No. 2, pp. 121-133.

Lewis, J.D. and Weigert, A. (1985), “Trust as a social reality", Social Forces, Vol. 63 No. 4, pp. 967-985.

René BOIREL. (1961), Théorie Générale de l'Invention, Presse Uni.

Rooke, J., Seymour, D. and Fellows, R. (2004), "Planning for claims: An ethnography of industry culture", Construction Management and Economics, Vol. 22 No. 6, pp. 655-662.

McConnell, S. (1996), Rapid Development: Taming Wild Software Schedules, Microsoft.

Wang, M. and Governatori, G. (2007), "A Logic Framework of Normative-based Contract Management", Artificial Intelligence, No. June.

Williamson, O. (1993), "Trust, and Economic Organization", Journal of Law and Economics, Vol. 36 No. 1, pp. 453-486.

Wong, W.K. et al. (2008), "A framework for trust in construction contracting", Elsevier Ltd and IPMA,, International Journal of Project Management, Vol. 26 No. 8, pp. 821-829. 